\title{
Automotive International Trade Networks: A comparative analysis over the last two decades
}

\author{
Sara Gorgoni \\ University of Greenwich
}

Alessia Amighini

University of Eastern Piedmont

Matthew Smith

University of Oxford

\begin{abstract}
This paper explores the structural changes in the international organisation of automotive production since the early 1990s. We apply descriptive network measures to international trade data for the period 1993-2013 for three automotive component groups with different technological intensity, with the aim of understanding: 1) How the automotive international trade network has changed since the beginning of the 1990s; 2) Whether regionalisation has increased over time; 3) How the role that rising powers play within and between regions interacts with regionalisation patterns. Our findings suggest that the structure of trade has changed significantly over the last two decades in all components. The network for electric and electrical parts and engines has evolved to become more hierarchical, with a cohesive core tied to hangers-on in the periphery, while the opposite has happened for rubber and metal. Regionalisation patterns also show important differences across components. Finally, we have found an apparent association between the strengthening of regionalisation patterns and the role played by traditional players and rising powers.
\end{abstract}




\section{JEL Classification: F14; F19}

Keywords: Automotive industry; Parts and components trade; Intermediate trade; Fragmentation; Regionalisation; Multipolarity; BRICs; Rising powers; Network analysis; Core-periphery; E-I Index; Brokerage roles.

\section{INTRODUCTION}

Whether international trade and production networks are regional or global has long been of great interest and importance to scholars and policy makers (Baldwin and Lopez-Gonzalez, 2014; Los et al, 2015). This interest has been kept alive by the fact that over the past quarter century we have witnessed important transformations to the way in which production is organised and trade is structured, with often concomitant yet opposing tendencies towards globalisation and regionalisation.

Over the last two decades, global trade and financial flows have registered unprecedented growth, to a great extent due to the increasing trade by the emerging economies, in particular the so-called BRICs (Brazil, Russia, India, China), but also by many low and middle income countries (many of which have doubled their total share of world exports) (Hanson, 2012). Among the reasons for that unprecedented growth of world trade is the increasing number of trade agreements between geographically distant countries since the early Nineties, with developing or emerging countries becoming very active in signing preferential trade agreements (PTAs), to the point that the vast majority of PTAs are now active between developing or emerging countries (Iapadre and Tajoli, 2014).

The 2007-2008 economic crisis had a substantial impact on the structure of production in most industries, accelerating the integration of emerging economies in the production process, where they have become increasingly important players (Hanson, 2012). In the automotive 
industry, the financial crisis resulted in an increased shift of production to developing countries, not only to take advantage of lower operating costs, but also to benefit from the strong sales growth in these nations especially when compared with mature markets in developed nations, where sales growth has slowed (Sturgeon and Van Biesebroeck, 2011).

Along with a shift of production activities to emerging economies in this industry, there has also been an increase of internationalisation activities by automakers from developing nations, enhancing their capabilities through a number of high-level acquisitions. The financial crisis provided the opportunity for auto firms from developing nations to acquire distressed auto firms from the traditional group of auto producers located in industrialised countries. For instance, in 2010, Geely, a Chinese firm, acquired Ford's Swedish car maker Volvo in a $\$ 1.8$ billion deal (The Economist, 2010). Other famous examples are India's Tata Motors' purchase of Jaguar and Land Rover from Ford for \$2.3 billion (The Economist, 2008).

At the same time, intra-regional economic linkages have also become much stronger, with the proliferation of regional trade agreements (RTAs) and common currency areas, pointing to two apparently contradictory trends. The number of RTAs increased dramatically in the Nineties and even more during the following decade. In particular, since the mid-Nineties a new wave of regional agreements has characterised former communist countries (Gaulier, Jean and Ünal-Kesenci, 2004). According to Gaulier, Jean and Ünal-Kesenci (2004) institutional arrangements have also consistently been found to be the leading explanation for increasing regionalisation in Western Europe, Southeast Asia and North America since the late Eighties.

With a different argument, Rugman (2008) reinforces the idea of regions as the central locus of governance of commercial activity. He argues that multinational corporations are actually regional firms with global interests, and points to a decline in economic globalisation and a steady increase in regional economic activity. 
Recent work in the area of the international political economy has identified two ways in which regionalism might emerge as an outcome or evolution of, or response to globalisation. On the one hand, it can be argued that rather than being contradictory trends, regionalism represents a stepping-stone on the way to globalisation, offering more protection than countries would experience in the global market. This is the notion of 'open regionalism', which is in contrast to the 'closed' regionalism of the 1960s and 1970s aimed at insulating members from the world economy in line with dependency theories. On the other hand, regionalism can be seen as an attempt by the State to resist the negative effects of globalisation in order to preserve domestic agendas - such as redistribution - that are threatened by globalisation. According to these views then, the two concomitant yet apparently opposite trends of regionalisation and globalisation could be complementary rather than contradictory (Nesadurai, 2002).

In this paper, we also examine how patterns of multipolarity interact with regionalisation trends, and more specifically, how the role that rising powers play within and between regions interacts with regionalisation patterns. ${ }^{1}$ Chen and De Lombaerde (2014) argue that while the growth strategies of the BRICs and their integration in the world production system has been extensively investigated, less attention has been paid to how integration in the global economy is related to integration in the regional economy.

Many studies (including among others, Clegg, 2009; Chen and Lombaerde, 2014; Garzón, 2016) argue that the BRICs phenomenon mirrors a general shift in the international balance of power, with the centre of gravity moving from the north to the south, and power becoming more distributed among multiple poles.

The fact that most of the rising powers are also the sole regional powers of their home regions has led some scholars to argue that the advent of multipolarity is likely to strengthen a trend towards a more regionalised international order. Others challenge this view, according to which especially in the global south where intraregional links tend to be weak, there may be 
centrifugal forces within regions (Garzón, 2016). In addition to looking at the extent to which regionalisation is linked to the degree of connectedness of the peripheral countries within the periphery, we also investigate whether regionalisation is linked to the brokerage roles played by individual countries, with a focus on the rising powers.

\section{RESEARCH QUESTIONS AND CONTRIBUTION}

In this paper we analyse the case of automotive parts and components to answer the following research questions: (i) How has the structure of trade changed over the last two decades, especially with the participation in the production process of emerging economies as new suppliers? (ii) Has regionalisation increased over time, and do tendencies towards regionalisation differ across automotive parts and component groups? (iii) How do patterns of multipolarity interact with regionalisation trends, and more specifically, how does the role played by rising powers within and between regions interact with regionalisation patterns?

Although it is beyond the scope of this paper to investigate the impact of the financial crisis on the structure of international trade, our analysis spans over two decades that include the 2008, allowing some insight into how the structure of trade in these components changed following the financial crisis, and consequent changes in the location patterns of components suppliers.

The automotive industry is well suited to answer the above research questions. This industry was traditionally shaped on a regional basis, with carmakers organised on a continental scale, in both commercial and productive aspects. However, the more recent vertical disintegration of carmakers and the consequent increase in the power of suppliers may have led, in some cases, to a growth in the international exchange of auto parts (Frigant and Zumpe, 2014). 
We have sought to answer our research questions by using highly disaggregated trade data for three automotive parts and components groups with different technological intensity (electric and electrical parts, engines, and rubber and metal). The use of parts and components trade as a suitable proxy for participation in international production networks is commonplace (Blázquez and González-Díaz, 2015). Since the 1990s, intermediate goods exchanges have represented an increasing proportion of the international goods trade (Feenstra, 1998). This evolution is widely recognised as being the result of the increased international fragmentation of production processes, mainly linked to three factors: the movement towards vertical disintegration of large firms that rely increasingly on outsourcing; the international division of labour set up by these firms; and the increased participation of new countries - such as China - in world trade (Frigant and Zumpe, 2014).

Network analysis can provide useful tools to analyse the structure of trade at both the regional and global level (Piccardi and Tajoli, 2012). The economic geography literature has emphasized that the relative position of the region within the whole network of interactions is a key issue faced by firms when choosing where to locate and thus also influences the way they organize their production, management and outsourcing patterns. Scholars in this area highlight how any change that directly involves one or two regions are unlikely to leave the remaining regions unaffected. Network analysis is, therefore, the ideal tool to capture these complex interdependencies (Blázquez and González-Díaz, 2015). In this paper we combine a plurality of network measures and network visualitation tools in order to understand how trade in automotive parts and components has changed over the last two decades and across components.

It is interesting to explore differences across auto parts and components, as these differ significantly in terms of factorial or technological intensity. These differences will influence transportation costs, transaction cost and the extent to which scale economies can be exploited, 
and are therefore reflected in companies' outsourcing and location decisions (Blázquez and González-Díaz, 2015).

To answer our first research question about changes in the structure of production and trade over the last two decades, we look at how the size and composition of the international trade network has changed in each automotive component group under examination. We also look at how the average number of trading partners, as well as the average value of trade flows has changed over time. Additionally, we look at whether the distribution of exports has become more skewed, with only a few countries accounting for most of the world trade, or whether export flows are evenly distributed in the network. Finally, we examine whether the international trade network for each component has evolved over time to become more hierarchical, with a cohesive core tied to hangers-on in the periphery.

Empirical studies analysing regionalisation and globalisation trends have been developed within different theoretical perspectives and seek to contribute to different literature strands, including international trade, international business and economic geography. Many of the studies investigating specifically the automotive industry have taken a Global Value Chain or Global Production Network perspective. This paper will refer to all of these different related literatures with the aim to contribute to the regionalisation debate by providing a detailed analysis of a specific industry. Sturgeon et al. (2009) provide several reasons of why analysis at the industry level is important. They also look at the automotive industry and explain why it presents some very distinctive features compared to other industries.

Measuring trade regionalization and detecting leadership patterns in regional trade networks may be done in a variety of ways, including the use of gravity models, intensity indices or network analysis tools. Iapadre and Tajoli (2014) for example apply the tools of network analysis in order to take into account whether local trade structures and preferential agreements affect the overall system of international trade and study the role of BRICs in the 
global and regional trade networks in three years 1995, 2008 and 2011. While their analysis and most of the discussion in the regionalisation literature - is at a more aggregated level, in this paper we look at a specific industry, because production is organised differently across industries, and findings at an aggregated level may not be valid at a more disaggregated level.

We therefore seek to answer the second research question about whether trade has become more or less regionalised by applying a weighted version of the E-I index. This measure enables an assessment of the degree of regionalisation and globalisation of individual countries as well as that of entire regions by revealing how much of the total value of trade of an individual country or region is within the region or across regions.

Furthermore, the paper aims to add to the literature on the role of rising powers in a multipolar world by looking at how patterns of regionalisation interact with the role that these powers play in the international trade network. While centrality measures have been used to answer questions similar to this one (see for example Iapadre and Tajoli, 2014), we believe that a more in-depth analysis of the role of emerging economies and in particular of rising powers that looks at the different brokerage roles these countries play may shed new light.

We therefore seek to answer our third research question about the role of rising powers within and between regions by performing a brokerage analysis of the BRIC countries.

The next section describes in detail the data and the methodology, while section four presents and discusses the findings, with the last section presenting the conclusions.

\section{DATA AND METHODOLOGY}

\subsection{DATA}

Following the empirical literature on production fragmentation, pioneered by Yeats (2001) and pursued in a number of recent studies (including Ng and Yeats, 2003; Athukorala, 2005; Kimura, 2006; Athukorala and Yamashita, 2008; Amighini and Gorgoni, 2013) we use bilateral 
trade statistics on auto parts and components trade from the UN trade data reporting system (UNComtrade database) ${ }^{2}$

Following Amighini and Gorgoni (2013), highly disaggregated trade data at product level are used as proxy for the production of automotive components. We have selected disaggregated trade data at 5 digits level, representing detailed product categories for each of the components used in automobile production, using the Standard International Trade Classification (SITC, Rev. 3). These components amounted to a total of 30 commodity groups. However, the products are far from being a single homogenous category, including relatively low technology parts such as various rubber and metal parts, as well as components with higher technological content such as computer equipment and electrical parts. As production fragmentation is largely driven by technological factors, different types of auto parts are likely to differ in the way production is organised across countries due to diverse technological content and value-to-weight ratios (Hummels, 2007). Therefore, we have aggregated 19 of the 30 commodity groups (4 electric and electrical, 9 rubber and metal parts, 6 engines) into 3 component groups with different technological content: electric and electrical parts, engines, and rubber and metal parts. ${ }^{3}$ For each of the three groups we take the bilateral trade flows in 1993, 2003 and 2013 as reference years to map the changes in the international structure of automotive production that have occurred since the beginning of the $1990 \mathrm{~s} .{ }^{4}$ The trade value for each given year represents the average over three years (the reference year and the preceding and following years, in order to smooth out random variations).

For each of the auto components examined, a value is given to the trade relationship (i.e. tie) between any two pairs of countries $[i j]$ according to the value of their bilateral trade flow [wij] over the world's total for that good in a specific year. We take the shares because we are interested in the relative position of each country in the network and its changes over time. 
As a criterion for setting the network boundary, only those countries with bilateral flows accounting for at least 0.01 per cent of the world's total have been included. This covers on average 95 per cent of all world trade (see Table 1). This threshold was selected to ensure that only the most relevant nations and ties were included in the network. Without a threshold a large number of nations would be included that contribute very little to international trade yet have a substantial impact on structural features of the network, such as reciprocity and density.

This paper also uses directed trade flows, which allows accounting for 'asymmetric dependence' (Silva and Teixeira, 2008: 283) in order to better analyse structural transformations shaped by globalisation and investigate the existence of hierarchical and coreperiphery structures.

Table 1 about here

Based on the trade data described, nine squared directed and valued matrices were created and analysed. In the network visualisations the nodes represent the countries and the ties represent the trade flows among them. The nodes are not the same in all the matrices, as some countries may be involved in the trade of some components but not others.

We have used network visualisation tools to show the changes occurring in the trade network for each component over time. In addition, we have calculated some network measures to describe and contrast the trade networks over time and across components.

\subsection{NETWORK MEASURES}

In order to identify changes over time and make comparisons across components, we have used some descriptive measures commonly used in social network analysis (SNA) to analyse the structure of a network (Wassermann and Faust, 1994). A first consideration is the difference in size (i.e. number of countries) and composition (which countries participate) of the networks 
over time and across components.

The number of trade partners a country has on average is also a useful indicator. In this study we are interested in the number of trade partners each country exports to. This is measured using Out-Degree Centrality (Knoke and Burt, 1983).

To account for the fact that a country may export to a high number of other countries (i.e. having a high Out-Degree Centrality), but these trade flows may be of little monetary value and represent overall only a small proportion of the value of global world trade, we also calculate a centrality measure that accounts for the value of each export tie (Freeman, 1979). ${ }^{5}$ In Table 3 this is referred to as Weighted Out-Degree Centrality (Out-Degree Centrality weighted by the monetary value of each tie).

Since a prevalence of asymmetric relationships might suggest a more hierarchical structure of the international organisation of production, we also calculate a network measure called Reciprocity, which provides the percentage of ties that are reciprocated (Wassermann and Faust, 1994).

To investigate whether there is a hierarchical structure within the network - with a cohesive core tied to hangers-on in the periphery - we perform a core-periphery analysis (Borgatti and Everett, 1999). ${ }^{6}$

To see whether exports are distributed evenly among a number of countries or whether they are instead concentrated on a few countries which account for most of the global bilateral exports, we compute the Out-Degree Centralisation (Freeman, 1979; Scott, 2000).

To assess whether production of each component group is organised into regional blocs, or whether trade is truly global we apply a weighted and normalised version of the E-I index. In its original formulation, the index only looks at the number of ties each country has within and across a partition (Krackhardt and Stern, 1988). In this paper we make use of a weighted variant of the E-I index that was developed by Danchev and Porter (2017) in their examination of the 
world migration network and instead of the number of trade ties, we consider the value of the trade flows. Below is the formulation of this weighted version of the E-I index:

$$
\text { Weighted E }- \text { I Index }=\frac{E_{w}-I_{w}}{E_{w}+I_{w}}
$$

Where:

- $E_{w}=$ External weight outside the region

- $I_{w}=$ Internal weight within the region

The Weighted E-I score can range from 1 to -1 , where positive values indicate that the majority of trade (value) occurs outside the region and negativevalues indicate that trade (value) is mostly regional. This index can be calculated at the country or regional level.

As noted by Borgatti et al. (2013) the E-I index at the regional level is somewhat sensitive to the size of the region. To address the group size disparity we calculate the weighted E-I index at the country level and take the average for each regional group, hence normalising the regional score by the number of countries in the region.

In order to assess the role that rising powers play at the regional level and how this interacts with regionalisation patterns in the sector, we make use of brokerage roles (Gould and Fernandez, 1989), examining the roles played by nations within and between regions. There are five brokerage roles (coordinator, gatekeeper, representative, consultant and liaison) which indicate different positions a country may hold.

Table 2 presents the five brokerage roles with a brief description and visualisation. A country is considered to be a coordinator if it imports from and exports to those in the same region.

A gatekeeper imports from a nation outside its region and exports to those within it. This role potentially indicates whether a country is a regional supplier in the sector. For example, 
the gatekeeper role is illustrated in the transit role of the Netherlands, which imports large volumes globally to redistribute them across Europe.

The representative role reflects the case of a country that imports from its own region but exports outside its region, linking its region to other regions.

Finally, the consultant and liaison roles denote the tendency for nations to participate in global trading relations rather than holding strong regional positons in the international trade network. Consultants act as external players, linking members belonging to the same region, which is a different one from its own. Liaisons tend to connect regions that are different, and different from its own, indicating that such countries hold a stronger position in the global production network (over regional production sites).

\section{Table 2 about here}

In addition to synthetic network measures, network visualisation techniques provide a very powerful descriptive tool. Figures 1, 2 and 3 provide representations of the trade networks for each of the components at three different intervals, over two decades. In the figures, the node and label colours reflect a geographical partition based on the World Bank classification of countries, which has been modified to create subcategories within the group 'Europe and Central Asia'. Our classification separately identifies the EU28 countries, countries which are part of Europe but not part of the EU (e.g. Norway and Switzerland), countries in Eurasia (e.g. Turkey) and countries in Central Asia (e.g. Kazakhstan). Nodes with the same colour belong to the same geographic area according to our regional classification.

The thickness of the lines reflects the value of the trade flow. Thicker lines represent trade flows of higher value. Finally, the different colours of the lines indicate whether the flow is within (blue) or between (red) regions, thus it visually provides a rough indication of the degree 
of regionalisation. A prevalence of blue suggests a high degree of regionalisation.

\section{FINDINGS AND DISCUSSION}

\subsection{Structural changes in automotive production and the role of new suppliers}

Table 3 provides some descriptive measures of the analysed networks, allowing a quick comparison. The first thing to note is that the networks analysed have different sizes (i.e. number of countries participating as exporters of automotive components).

Table 3 about here

All the networks changed over time, showing both an increase in size and a change in the country composition (see Table 4), with some countries from Central and Eastern Europe (such as Poland, Russia and Slovakia) and Asia (such as China, India, Indonesia and Thailand) becoming component suppliers only in the twenty-first century.

Table 3 also indicates the average number of exporting partners for each country in each network, based on the average Out-Degree Centrality of countries in the network. The table shows that the average number of export partners increased over time for all components, while the Weighted Out-Degree Centrality scores show that the average value of ties decreased.

Table 4 about here

Out-Centralisation is a measure of how exports are distributed among all countries. In the study, this measure declined over time for all the components, suggesting that exports have become more evenly distributed across countries since the 2000s, that is, a larger number of countries now account for most of the world's export flows compared with 1993. 
It is worth noting that for electric and electrical parts, and also rubber and metal parts, Reciprocity was stable over the two decades studied, while for engines it increased over time, hinting at the division of labour becoming less hierarchical over time.

The core-periphery measure looks at the extent to which there is simultaneously a group of countries that are tied in together by commercial bonds and who intensively import and export from each other, and a group of countries that is connected to the core very weakly, often by no more than one export or import tie. The results in Table 3 reveal that the network for electric and electrical parts has evolved towards a more core-periphery structure over time. This has happened alongside a shrinking of the core and the participation in the core of new countries. In the case of electric and electrical parts, the core of the 1993 network included BelgiumLuxembourg, France, Germany, Hong Kong, Italy, Japan and the UK. Over time the core shrank to only five countries in 2003, namely the US, Japan, Mexico, China and Hong Kong, and, in 2013, China, Japan, Mexico, the Republic of Korea and the US. Remarkably, China was importing from only a few countries in 1993 but just a decade later entered the core as an exporter to all other countries in the core.

Figure 1 about here

In 1993 China was trading in electric and electrical parts intensively only with Hong Kong and weakly with a limited number of European countries (Figure 1-a). The picture changed dramatically over the following decade (Figure 1-b) whereby in the early twenty-first century China had become a bigger exporter, very central to the network, forming part of the core and brokering across different regions, as shown by the prevalence of red ties representing trade flows between the regions (Figure 1-c).

The Table 3 results for engines show an increased density in trade flows within the core, 
accompanied by an increase in trade flows from the core to the periphery. Despite a very small increase within the periphery, the core-periphery measure for engines suggests that the network has become characterised over time by a structure of trade that is increasingly concentrated around the core, with very little happening elsewhere.

Thus, the results of the core-periphery analysis on the electric and electrical parts and engines point to a change in the international organisation of auto production towards a more hierarchical structure, with parts suppliers exporting to one or a few single major destinations, but having no relationships with other supplying countries.

It is also worth noting that, in the case of engines, the core has become smaller over time, going from nine countries in 1993 - including Austria, Belgium-Luxembourg, France, Germany, Italy, Japan, Spain, Sweden and the UK to just three countries in 2003 and 2013: Canada, Mexico and the US.

Figure 2 shows an increased participation of new countries in the production and trade of engines over time. Figures 2-b and 2-c show the strengthening in 2003 and 2013 of Germany's role as a main player in Europe and worldwide in the production of engines, but also Eastern European countries such as Poland, Hungary and the Czech Republic becoming increasingly embedded in the network as important parts suppliers. The figures also show the increased participation over time of East Asian countries such as China, Japan and South Korea.

Figure 2 about here

The case of rubber and metal parts is somewhat different from the other two components. Table 3 shows that trade flows for rubber and metal parts within the core declined over the time period studied, with trade flows from the periphery to the core increasing, suggesting a more even distribution of trade flows across countries, and thus a less hierarchical division of labour. 
The case of rubber and metal is also different in the sense that the size of the core declined between 1993 and 2003 but then grew again over the latter decade. However, as with the electric and electrical parts and engine, a change can be observed over time in the composition of the core and the role played by emerging economies, with countries such as China entering the core in 2013 (Table 3), and the Czech Republic and Poland becoming central in Europe (Figures 3$\mathrm{b}$ and $3-\mathrm{c})$.

Figure 3 about here

\subsection{Regionalisation in the automotive production network and the role of regional rising} powers

Table 5 shows brokerage roles for the rising powers, along with the US, Germany and Japan, which are the traditional dominant players in the sector. The US has consistently held a strong liaison role in the international trade network across component groups. Results are presented for 2003 and 2013 to reflect the changes in the roles played by the rising powers in the sector before and after the financial crisis, given that it accelerated the integration of emerging economies into the industry.

Table 5 about here

\subsubsection{Electric and electrical parts}

For electric and electrical parts, the weighted E-I index in Table 6 indicates that both EU28 and East Asia \& Pacific are characterised by strong regionalisation. This is also shown by the heat-map in Figure 4, which provides a visual representation of the index, where the yellow zones reflect a tendency towards regionalisation. 
Figure 4 about here

From Figure 1 also, it can be seen that East Asia \& Pacific is characterised by a high level of regionalisation that has slightly increased over time, and there is an emergence of an Asian regional production network (in the figure, Asian countries are strongly inter-connected by blue ties), which is also highly embedded in the global production network (red ties). The weighted E-I index for Eurasia, Latin America and the Caribbean, other European countries, South Asia and Sub-Saharan Africa shows that the value of inter-regional ties exceeds the value of intraregional ties, but the former has declined over time. In the case of Sub-Saharan Africa, for example, it is evident that when looking at the value of trade, the relative importance of intraregional trade has increased over time.

China and Japan represent two dominant players in the East Asia and the Pacific region. They both hold gatekeeper roles as shown in Table 5, importing from outside the region and distributing exports within the region, therefore acting as regional suppliers.

Table 6 about here

The emergence of an Asian production network has been accompanied by a strengthening of the European production network with the incorporation over time of a new set of players, mainly from Eastern Europe, acting as important suppliers to the world's leading car producers, shown, for instance, by the increased centrality of the Czech Republic and Poland. It thus appears that there is now a much larger number of suppliers located in different countries from those of the major producers (OEM), with Germany still playing a leading gatekeeper role.

The Latin America \& Caribbean region is not characterised by regionalisation trends to the same extent as observed in EU28 and East Asia \& Pacific. Table 6 shows that the weighted E- 
I index for this regional partition is positive (most of the value of trade flows is across regions), but the score has been declining over time. In this region, Brazil holds a representative role, linking the region to other regions, such as North America. Overall these results suggest that regionalisation patterns may be associated with transit roles (such as gatekeeper) for the key players in the region.

\subsubsection{Engines}

In the case of engines, the weighted E-I index in Table 6 and the heat-map in Figure 5 indicate strong regionalisation for EU28, East Asia \& Pacific and North America, but this is declining over time. In the case of Latin America \& Caribbean instead, most of the value of trade is beyond the region rather than within, and the degree of global integration has strengthened over time. The remaining regions analysed seem to be highly globally integrated, with most of the value of trade coming from inter-regional ties.

Figure 2 shows that while there has always been a European production network (indicated by the blue ties among EU28 countries), this became stronger in 2003. Since 2013, however, these regional production networks have become strongly embedded in global trade (red ties, indicating trade flows between regions), with Figure 2-c showing a prevalence of red ties.

The traditional leaders, Japan and Germany, have both shifted from being only gatekeepers to also holding liaison roles (linking countries from regions different than their own), while the rising powers in this product group have come to hold a combination of liaison and representative roles (import from their own region and export outside their region, thus acting as global distributors). It appears that, in this product group, rising powers are becoming increasingly integrated into the international production network by establishing global trade ties and linking their geographic region to the global network. 


\subsubsection{Rubber and metal parts}

The weighted E-I index results for rubber and metal components shown in Table 6 and Figure 6 indicate that East Asia \& Pacific and EU28 are both characterised by regionalisation trends. Both Germany and Japan, two traditional leaders, have strong gatekeeper roles, while the emerging economies hold representative roles. The representative role potentially indicates that these countries are further integrating globally by linking their region to other in the international production network. Looking at Figures 3-b and 3-c, regional production networks can be seen for East Asia \& Pacific, EU28 and Latin America \& Caribbean, but these are embedded in global (red) ties.

\subsection{Discussion of findings}

Blázquez and González-Díaz (2015) in their analysis of the automotive industry provide a general descriptive analysis of the network of final goods along with automotive parts and components. Similarly to our findings, they find that the network has become denser and more extensive over time since countries have, on average, increased the number of partners with which they trade. However, while we find that export centralisation has decrease over time across all components, meaning that exports have become more evenly distributed across a higher number of countries, these authors find that exports have become more concentrated. Both our study and their study agree, however, on the fact that the network of auto parts and components has maintained a core-periphery structure, in which regional clusters have arisen and hubs have become increasingly important. The authors conclude that although agglomeration forces clearly prevail in the world auto trade network and spatial imbalance remains, centrifugal forces are expanding the network around new areas.

Iapadre and Tajoli (2014), in their analysis at an aggregated level reach a different conclusion, finding that the degree of trade regionalization has fallen substantially between 
1995 and 2011 in all the four regions covered, and show that the forces driving towards global integration have been stronger than the trade-diverting effects of regional integration. We find this to be the case for engines, but not for the other two components.

The fact that the literature doesn't reflect a consensus demonstrates how important the level of aggregation are, suggesting that results found at an aggregated level may not apply at a more disaggregated, industry specific, level. Sturgeon et al. (2009) in their analysis of the automotive industry highlight how global, regional, national and local value chains are nested to create a pattern of global integration that is distinctive to the industry.

Consistently with their and other studies (see for example Frigant and Zumpe, 2014), our analysis shows that the degree of regionalisation and globalisation of trade in auto parts is heterogeneous across regions and components. Overall the EU28 and East Asia \& the Pacific are characterised by relatively few far-distance flows. On the contrary, other regions rely more heavily on far-distance flows. The European case is particularly striking. The 2000-2012 period witnessed the enlargement of the Union towards Eastern and Central Europe. This evolution enabled suppliers to discover new areas (in Eastern Europe primarily) in order to segment their production process on a larger scale and profit from the differences between countries (e.g. labour costs, labour legislation, etc.).

In Sub-Saharan Africa and the Middle East production networks tend to expand over long distances. This is again consistent with Frigant and Zumpe's (2014) findings in their study of the automotive industry.

Our findings show that in North America far-distant flows increased significantly over the period examined for two of the thee components, namely engines and rubber\&metal. Frigant and Zumpe (2014) suggest four factors that may explain this trend: 1) exhaustion of the process of regional integration, which in this region started earlier; 2) the entry of China into the World Trade Organisation in 2001, which offered new localisation opportunities for low cost 
production of components destined for both original car equipment and the spare parts market; 3) specific regulations that compel certain production types in the areas (this is the case with rare earth restrictions in China for example); and 4) the financial crisis that impacted the United States heavily from 2008 which forced many suppliers to shut down their North American production sites at a time when they were setting up new production capacities in Asia. The last three points are also made by Sturgeon and Van Biesebroeck (2011).

Overall, when examining the brokerage role of rising powers and the traditional key players in the industry, there seems to be an association between the strengthening of regionalisation patterns and traditional players (such as Japan and Germany) acting as gatekeepers. The results also indicate an increased tendency for the rising powers to link their regions to the international trade network, along with taking representative or global liaison roles. The exception to this is China in the case of electric and electrical parts, where it plays a gatekeeper role at the centre of a new Asian regional production network. These findings suggest that traditional players and rising powers play different roles within each region; while the former seem to maintain gatekeeper roles, strengthening regionalisation patterns over time, rising powers have come to play a more international role.

In his analysis of global production sharing in East Asia, Athukorala (2011) concludes that while economic interdependence among countries in the region has strenghtened over time, with China playing a pivotal role as the premier center of final assembly, this has not lessened the dependence of the export dynamism of these countries on the global economy. He argues that the rise of global production sharing has strengthened the case for a global, rather than regional, approach to trade and investment policymaking.

This finding is in line with those of Iapadre and Tajoli (2014). Their results show that the BRICs are the most globalized countries in terms of connectivity to the world trading system in each of their respective regions, suggesting that given the advantage of this position, they 
could play the important role of linking smaller nearby countries to the large international markets. They conclude that insofar as PTAs give rise to outward looking structures, they can be useful policy instruments for development. While there is a risk for the smaller countries to become dependent on a very strong centre, the authors suggest that this link can be their best chance to grow as exporters.

\section{CONCLUSION}

Over the past quarter century, the forces of regionalisation and globalisation, the participation of new emerging economies and the financial crisis have significantly transformed the organisation of production.

In this paper we have analysed the case of automotive parts and components trade in seeking answers to the following questions: 1) Has the structure of trade changed over the last two decades, especially with the participation in the production process of emerging economies as new suppliers? 2) Has regionalisation increased over time, and do tendencies towards regionalisation differ across automotive components groups? 3) How do patterns of multipolarity interact with regionalisation trends, and more specifically, how does the role that rising powers play within and between regions interact with regionalisation patterns?

We have sought to answer these questions by applying network measures to highly disaggregated trade data for three automotive parts and components groups with different technological intensity (electric and electrical parts, engines, and rubber and metal).

Our findings suggest that with respect to the first research question the structure of trade in automotive components has changed significantly over the last two decades, especially with the participation of emerging economies in the production process as new suppliers. This is particularly visible in the case of electric and electrical parts, with a leading role being played by China and Eastern European countries. The average number of exporting partners has 
increased over time for all components, while the average value of ties has decreased over time for all components except engines. This shows the rising number of suppliers to major auto producers, and these suppliers are located in many emerging and developing countries that are now participating to international production networks in the sector, unlike in the past. The engine subsector runs counter this trend, as it has remained more oligopolistic, with a fewer number of suppliers.

Despite the fact that exports in all parts and components examined have become more evenly distributed across countries since the 2000s, the network for electric and electrical parts and engines has evolved into a more core-periphery structure over time. This has been accompanied by a shrinking of the core and the participation of new countries. The case of rubber and metal suggests instead a move towards a less hierarchical division of labour.

With respect to the second research question regarding tendencies towards regionalisation, our results show important differences across different automotive components and regions. For example, while there has been a strengthening of regionalisation in EU28 and East Asia, particularly in electric and electrical parts, and the emergence of a new regional production network, while other regions seem to show a prevalence of long-distance ties. The literature does not show a consensus on this aspect, and one possible explanation is that the level of aggregation matters, and findings at a more aggregated level may conflict with those obtained on a specific industry; even more so when looking at the trade in parts and components within a specific industry. These differences are especially relevant for policy decision-making.

With respect to our third and last research question about how the brokerage role of rising powers interacts with regionalisation patterns, there seems to be an association between the strengthening of regionalisation patterns and traditional players (such as Japan and Germany) acting as gatekeepers. The brokerage roles also indicate an increased tendency for the rising powers to take representative and liaison roles and link their regions to the international trade 
network. The exception to this is China in the case of electric and electrical parts, where it plays a gatekeeper role at the centre of a new Asian regional production network. These results seem to suggest that traditional players and rising powers play different roles within each region; while the former maintain gatekeeper roles, strengthening regionalisation over time, rising powers have come to play a more international role. Given the advantage of their position, these powers could play an important role in linking smaller countries to the large international markets, helping to build a multipolar world characterised by a more even distribution of power. 


\section{REFERENCES}

Amighini, A. and Gorgoni, S. (2014) The International Reorganisation of Auto Production, The World Economy, 37(7), pp. 923-952.

Athukorala, P-C. (2005) Product Fragmentation and Trade Patterns in East Asia, Asian Economic Papers, 4(3), pp.1-27.

Athukorala, P-C. and Yamashita, N. (2008) Patterns and Determinants of Production Fragmentation in World Manufacturing Trade. In di Mauro, F., Dees, S. and McKibbin, W. (eds), Globalisation, Regionalism and Economic Interdependence. Cambridge: Cambridge University Press, 45-72.

Athukorala, P-C. (2011) Production Networks and Trade Patterns in East Asia: Regionalization or Globalization?*, Asian Economic Papers, 10(1), pp. 65-95.

Baldwin, R. and Lopez-Gonzalez, J. (2014) Supply-chain Trade: A Portrait of Global Patterns and Several Testable Hypotheses, The World Economy.

Blázquez, L. and González-Díaz, B. (2015) International automotive production networks: how the web comes together, Journal of Economic Interaction and Coordination, pp. 1-32.

Borgatti, S.P. and Everett, M.G. (1999) Models of core/periphery structures, Social Networks, 21, pp.375-395.

Borgatti, S. P., Everett, M. G. and Johnson, J. C. (2013) Analyzing Social Networks, SAGE.

Chen, L. and De Lombaerde, P. (2014) Testing the Relationships Between Globalization, Regionalization and the Regional Hubness of the BRICs, Journal of Policy Modeling 36(S1):111-131.

Clegg, J. (2009) China's global strategy towards a multipolar world. New York: Pluto Press.

Danchev, V. and Porter, M. A. (2017) Neither global nor local: Heterogeneous connectivity in spatial network structures of world migration, Social Networks.

Feenstra, R.C. (1998) Integration of Trade and Disintegration of Production in the Global Economy, Journal of Economic Perspectives, 12(4), pp. 31-50.

Freeman, L. (1979) Centrality in social networks: conceptual clarifications, Social Networks, 23(1), pp. 215-239.

Frigant, V. and Zumpe, M. (2014) Are automotive global production networks becoming more global? Comparison of regional and global integration processes based on auto parts trade data. MPRA Paper No. 55727.

Garzón, J.F. (2016) Multipolarity and the future of economic regionalism, International Theory, pp. 1-35. doi: 10.1017/S1752971916000191.

Gaulier, G., Jean, S. and Ünal-Kesenci, D. (2004) Regionalism and the regionalisation of international trade. In CEPII Working Paper (2004-16).

Gould, J. and Fernandez, J. (1989) Structures of mediation: A formal approach to brokerage in transaction networks, Sociological Methodology, pp.89-126.

Hanson, G.H. (2012) The rise of middle kingdoms: Emerging economies in global trade, Journal of Economic Perspectives, 26, pp.41-64.

Hummels, D. (2007) Transport Costs and International Trade in the Second Era of Globalization, Journal of Economic Perspectives, 21(2), pp. 131-154. 
Iapadre, P.L. and Tajoli, L. (2014) Emerging Countries and Trade Regionalization. A Network Analysis, Journal of Policy Modeling, 36S (2014) S89-S110.

Kimura, F. (2006) International Production and Distribution Networks in East Asia: 18 Facts, Mechanics, and Policy Implications, Asian Economic Policy Review, 1(1), pp.346-347.

Knoke, D. and Burt, R. (1983) Prominence. In Burt, R.S. and Minor, M. J. (eds), Applied Network Analysis. Beverly Hills: Sage, 195-222.

Krackhardt, D. and Stern, R.N. (1988) Informal networks and organizational crises: an experimental simulation, Social Psychology Quarterly, 51(2), pp.123-140.

Los, B., Timmer, M. P. and de Vries, G. J. (2015) How Global Are Global Value Chains? A New Approach to Measure International Fragmentation, Journal of Regional Science, 55(1), pp. 66-92.

Nesadurai, H. (2002) Globalisation and Economic Regionalism: A Survey and Critique of the Literature, CSGR Working Paper No. 108/02. Center for the Study of Globalisation and Regionalisation (CSGR).

Ng, F. and Yeats, A. (2003) Major Trade Trends in East Asia: What are Their Implications for Regional Cooperation and Growth? Policy Research Working Paper 3084, Washington DC: World Bank.

Piccardi, C. and Tajoli, L. (2012) Existence and significance of communities in the world trade web, Physical Review E, 85(6), p. 066119.

Rugman, A. (2008) Regional multinational and the myth of globalisation. In Cooper, A.F., Hughes, C.W. and De Lombaerde, P. (eds) Regionalisation and Global Governance. The taming of globalisation? Routledge. Ch. 5.

Scott, J. (2000) Social Network Analysis. A handbook. London: Sage Publications. $2^{\text {nd }}$ edn.

Silva E. G. and Teixeira, A.C. (2008) Surveying structural change: Seminal contributions and a bibliometric account, Structural Change and Economic Dynamics 19.

Sturgeon, T. J., Memedovic, O., Van Biesebroeck, J. and Gereffi, G. (2009) Globalisation of the automotive industry: main features and trends, International Journal of Technological Learning, Innovation and Development, 2(1), pp. 7-24.

Sturgeon, T. J. and Van Biesebroeck, J. (2011) Global value chains in the automotive industry: an enhanced role for developing countries?, International Journal of Technological Learning, Innovation and Development, 4(1), pp. 181-205.

The Economist (2008) Now what?, The Economist, Available at http://www.economist.com/node/10925609.

The Economist (2010) Devolving Volvo, The Economist, Available at http://www.economist.com/node/15804598.

Wasserman, S. and Faust, K. (1994) Social network analysis: methods and applications. Cambridge: Cambridge University Press.

Yeats, A. (2001) Just How Big is Global Production Sharing? In Arndt, S. and Kierzkowski, H. (eds), Fragmentation: New Production Patterns in the World Economy. New York: Oxford University Press, 108-43. 


\section{Tables}

Table 1 Percentage of world trade covered by threshold

\begin{tabular}{|c|c|c|}
\hline Threshold & $\mathbf{0 . 0 1 \%}$ & $\mathbf{0 . 0 0 1 \%}$ \\
\hline & \multicolumn{2}{|c|}{ Coverage of world trade (\%) } \\
\hline Electric and electrical parts & 96.39 & 98.17 \\
\hline 1993 & 92.50 & 96.40 \\
\hline 2003 & 93.39 & 97.92 \\
\hline 2013 & & 99.90 \\
\hline Engines & 98.37 & 99.55 \\
\hline 1993 & 95.4 & 99.56 \\
\hline 2003 & 94.85 & 99.14 \\
\hline 2013 & & 97.15 \\
\hline 1993 & 97.09 & 97.73 \\
\hline 2003 & 91.66 & \\
\hline 2013 & 92.35 & \\
\hline
\end{tabular}

Table 2 Brokerage Roles

\begin{tabular}{|c|c|c|}
\hline Brokerage Role & Visualisation & Description \\
\hline Coordinator & & $\begin{array}{l}\text { Coordinators link countries in the same region, } \\
\text { deepening region production sharing. }\end{array}$ \\
\hline Gatekeeper & & $\begin{array}{l}\text { Gatekeepers import from other regions and then } \\
\text { distribute exports in their own region, therefore } \\
\text { acting as a regional supplier. }\end{array}$ \\
\hline Representative & & $\begin{array}{l}\text { Representatives import from their own region and } \\
\text { export outside the region. These nations act as } \\
\text { global distributors for their region. }\end{array}$ \\
\hline Consultant & & $\begin{array}{l}\text { Consultants link countries from the same region, } \\
\text { where they act as external players to regional } \\
\text { production networks. }\end{array}$ \\
\hline Liaison & & $\begin{array}{l}\text { Countries acting as Liaisons link countries from } \\
\text { different regional partitions. }\end{array}$ \\
\hline
\end{tabular}


Table 3 Results table - Descriptive network measures

\begin{tabular}{|c|c|c|c|c|c|c|c|c|c|}
\hline & \multicolumn{3}{|c|}{ Electric and electrical parts } & \multicolumn{3}{|c|}{ Engines } & \multicolumn{3}{|c|}{ Rubber and metal parts } \\
\hline & 1993 & 2003 & 2013 & 1993 & 2003 & 2013 & 1993 & 2003 & 2013 \\
\hline Network size & 84 & 86 & $105 \uparrow$ & 73 & 65 & 73 & 90 & 113 & 111 \\
\hline Reciprocity & 0.15 & 0.10 & 0.16 & 0.12 & 0.18 & $0.23 \uparrow$ & 0.15 & 0.28 & 0.15 \\
\hline $\begin{array}{c}\text { Exports } \\
\text { concentration } \\
\text { (Out } \\
\text { Centralisation) } \\
\end{array}$ & $30.53 \%$ & $26.24 \%$ & $24.99 \%$ & $38.81 \%$ & $31.74 \%$ & $34.21 \%$ & $39.84 \%$ & $25.83 \%$ & $26 \%$ \\
\hline $\begin{array}{l}\text { Avg of export } \\
\text { partners (Out- } \\
\text { Degree } \\
\text { Centrality) }\end{array}$ & 3.66 & 6.95 & 7.26 & 3.44 & 7.00 & 7.71 & 4.93 & 7.32 & 8.66 \\
\hline $\begin{array}{l}\text { Avg_of export } \\
\text { flow value } \\
\text { (Weighted out- } \\
\text { Degree } \\
\text { Centrality) } \\
\end{array}$ & 0.181 & 0.168 & 0.153 & 0.188 & 0.274 & 0.302 & 0.253 & 0.162 & 0.154 \\
\hline \multirow{4}{*}{$\begin{array}{c}\text { Core-periphery } \\
\text { (C-P) } \\
\text { (Final fitness) }\end{array}$} & $\mathbf{C} \quad \mathbf{P}$ & $\mathbf{C} \quad \mathbf{P}$ & $\mathbf{C} \quad \mathbf{P}$ & $\mathbf{C} \quad \mathbf{P}$ & C $\quad \mathbf{P}$ & $\mathbf{C} \quad \mathbf{P}$ & $\mathbf{C} \quad \mathbf{P}$ & $\mathbf{C} \quad \mathbf{P}$ & $\mathbf{C} \quad \mathbf{P}$ \\
\hline & C 1.150 .07 & C 1.510 .02 & C $1.36 \quad 0.01$ & C 0.940 .03 & C 3.750 .06 & C 3.080 .06 & C 2.050 .070 & C $2.20 \quad 0.04$ & C 0.520 .02 \\
\hline & $\begin{array}{lll}\mathbf{P} & 0.01 & 0.00 \\
\end{array}$ & $\begin{array}{lll}\mathbf{P} & 0.05 & 0.00 \\
\end{array}$ & $\begin{array}{lll}\mathbf{P} & 0.05 & 0.00 \\
\end{array}$ & $\begin{array}{lll}\mathbf{P} & 0.02 & 0.00 \\
\end{array}$ & $\begin{array}{lll}\mathbf{P} & 0.01 & 0.02 \\
\end{array}$ & $\begin{array}{lll}\mathbf{P} & 0.01 & 0.01 \\
\end{array}$ & $\begin{array}{lll}\mathbf{P} & 0.02 & 0.00 \\
\end{array}$ & $\begin{array}{lll}\mathbf{P} & 0.03 & 0.00\end{array}$ & $\begin{array}{lll}\mathbf{P} & 0.03 & 0.00\end{array}$ \\
\hline & $(0.62)$ & $(0.56)$ & $(0.63)$ & $(0.48)$ & $(0.65)$ & $(0.65)$ & $(0.75)$ & $(0.62)$ & $(0.48)$ \\
\hline $\begin{array}{l}\text { Countries in the } \\
\text { core }\end{array}$ & $\begin{array}{c}\text { Belgium- } \\
\text { Luxembourg, } \\
\text { France, } \\
\text { Germany, Hong } \\
\text { Kong, Italy, } \\
\text { Japan, UK. }\end{array}$ & $\begin{array}{l}\text { China, Hong } \\
\text { Kong, Japan, } \\
\text { Mexico, US. }\end{array}$ & $\begin{array}{l}\text { China, Japan, } \\
\text { Mexico, } \\
\text { Republic of } \\
\text { Korea, US. }\end{array}$ & $\begin{array}{c}\text { Austria, } \\
\text { Belgium- } \\
\text { Luxembourg, } \\
\text { France, } \\
\text { Germany, } \\
\text { Italy, Japan, } \\
\text { Spain, } \\
\text { Sweden, UK. }\end{array}$ & $\begin{array}{c}\text { Canada, } \\
\text { Mexico, US. }\end{array}$ & $\begin{array}{c}\text { Canada, } \\
\text { Mexico, US. }\end{array}$ & $\begin{array}{c}\text { Belgium- } \\
\text { Luxembourg, } \\
\text { France, } \\
\text { Germany, Italy, } \\
\text { UK. }\end{array}$ & $\begin{array}{c}\text { Canada, } \\
\text { Japan, US. }\end{array}$ & $\begin{array}{c}\text { Canada, } \\
\text { China, } \\
\text { Germany, } \\
\text { Japan, } \\
\text { Mexico, } \\
\text { Republic of } \\
\text { Korea, US. }\end{array}$ \\
\hline
\end{tabular}




\begin{tabular}{|c|c|c|}
\hline & & Countries \\
\hline \multirow{3}{*}{$\begin{array}{c}\text { Electric } \\
\text { and } \\
\text { electrical } \\
\text { parts }\end{array}$} & $\begin{array}{l}1 \\
9 \\
9 \\
3\end{array}$ & $\begin{array}{l}\text { Argentina, Australia, Austria, Bahrain, Belgium-Luxembourg, Benin, Brazil, Bulgaria, Canada, Chile, China, Costa Rica, Cyprus, Czech Republic, Côte } \\
\text { d'Ivoire, Democratic People's Republic of Korea, Denmark, Djibouti, Egypt, El Salvador, Estonia, Ethiopia, Fiji, Finland, France, French Guiana, } \\
\text { Germany, Ghana, Greece, Guadeloupe, Guatemala, Honduras, Hong Kong, Hungary, Indonesia, Ireland, Israel, Italy, Jamaica, Japan, Jordan, Kenya, } \\
\text { Kuwait, Lithuania, Malaysia, Mali, Malta, Martinique, Mauritius, Mexico, Morocco, Netherlands, New Zealand, Nicaragua, Niger, Norway, Oman, } \\
\text { Pakistan, Panama, Peru, Philippines, Poland, Portugal, Qatar, Republic of Korea, Russia, Réunion, Saudi Arabia, Senegal, Serbia and Montenegro, } \\
\text { Singapore, Slovenia, Spain, Sweden, Switzerland, Syria, Thailand, The Former Yugoslav Republic of Macedonia, Trinidad and Tobago, UK, US, United } \\
\text { Arab Emirates, Uruguay, Venezuela }\end{array}$ \\
\hline & $\begin{array}{l}\mathbf{2} \\
\mathbf{0} \\
\mathbf{0} \\
\mathbf{3}\end{array}$ & $\begin{array}{l}\text { Algeria, Argentina, Australia, Austria, Bahamas, Bangladesh, Belarus, Belgium, Bosnia Herzegovina, Botswana, Brazil, Bulgaria, Canada, Chile, } \\
\text { China, Colombia, Costa Rica, Croatia, Czech Republic, Côte d'Ivoire, Denmark, Dominican Republic, Ecuador, El Salvador, Finland, France, Germany, } \\
\text { Greece, Guatemala, Honduras, Hong Kong, Hungary, India, Indonesia, Iran, Ireland, Israel, Italy, Japan, Kazakhstan, Kuwait, Lebanon, Lithuania, } \\
\text { Luxembourg, Macao, Malaysia, Mexico, Morocco, Mozambique, Namibia, Netherlands, New Zealand, Nigeria, Norway, Oman, Pakistan, Panama, } \\
\text { Paraguay, Peru, Philippines, Poland, Portugal, Republic of Korea, Romania, Russia, Saudi Arabia, Singapore, Slovakia, Slovenia, South Africa, Spain, } \\
\text { Sri Lanka, Sudan, Sweden, Switzerland, Thailand, Tunisia, Turkey, UK, US, Ukraine, United Arab Emirates, Uruguay, Venezuela, Vietnam, Yemen }\end{array}$ \\
\hline & $\begin{array}{l}2 \\
0 \\
1 \\
3\end{array}$ & $\begin{array}{l}\text { Algeria, Argentina, Australia, Austria, Bahamas, Belarus, Belgium, Bolivia, Bosnia Herzegovina, Botswana, Brazil, Bulgaria, Cambodia, Cameroon, } \\
\text { Canada, Chile, China, Colombia, Costa Rica, Croatia, Cyprus, Czech Republic, Côte d'Ivoire, Denmark, Dominican Republic, Ecuador, Egypt, El } \\
\text { Salvador, Estonia, Ethiopia, Finland, France, Georgia, Germany, Ghana, Greece, Guatemala, Honduras, Hong Kong, Hungary, India, Indonesia, Ireland, } \\
\text { Israel, Italy, Japan, Jordan, Kazakhstan, Kenya, Kuwait, Latvia, Lebanon, Libya, Lithuania, Malaysia, Mali, Mexico, Morocco, Mozambique, Nepal, } \\
\text { Netherlands, New Zealand, Nicaragua, Nigeria, Norway, Occupied Palestinian Territory, Oman, Pakistan, Panama, Paraguay, Peru, Philippines, Poland, } \\
\text { Portugal, Qatar, Republic of Korea, Romania, Russia, Saudi Arabia, Serbia, Singapore, Slovakia, Slovenia, South Africa, Spain, Sri Lanka, Sudan, } \\
\text { Sweden, Switzerland, Thailand, The Former Yugoslav Republic of Macedonia, Tunisia, Turkey, UK, US, Uganda, Ukraine, United Arab Emirates, } \\
\text { United Republic of Tanzania, Uruguay, Venezuela, Vietnam, Yemen, Zambia, Zimbabwe }\end{array}$ \\
\hline \multirow{3}{*}{ Engines } & $\begin{array}{l}1 \\
9 \\
9 \\
3\end{array}$ & $\begin{array}{l}\text { Argentina, Australia, Austria, Bahrain, Barbados, Belarus, Belgium-Luxembourg, Brazil, Bulgaria, Canada, Chile, China, Costa Rica, Croatia } \\
\text { Czech Republic, Denmark, Ecuador, Egypt, El Salvador, Fiji, Finland, France, Germany, Ghana, Guadeloupe, Guatemala, Honduras, Hong Kong, } \\
\text { Hungary, India, Ireland, Israel, Italy, Jamaica, Japan, Kenya, Malaysia, Malta, Martinique, Mauritius, Mexico, Morocco, Netherlands, Norway, Pakistan, } \\
\text { Peru, Philippines, Poland, Portugal, Republic of Korea, Romania, Russia, Réunion, Saudi Arabia, Serbia and Montenegro, Singapore, Slovakia, Slovenia, } \\
\text { Spain, Suriname, Sweden, Switzerland, Syria, Thailand, Tunisia, Turkey, UK, US, United Arab Emirates, Uruguay, Venezuela, Zimbabwe }\end{array}$ \\
\hline & $\begin{array}{l}\mathbf{2} \\
\mathbf{0} \\
\mathbf{0} \\
3\end{array}$ & $\begin{array}{l}\text { Algeria, Argentina, Australia, Austria, Belarus, Belgium, Botswana, Brazil, Canada, Chile, China, Colombia, Costa Rica, Croatia, Cuba, Czech Republic, } \\
\text { Denmark, Dominican Republic, Egypt, Finland, France, Germany, Greece, Guatemala, Hong Kong, Hungary, India, Indonesia, Iran, Ireland, Israel, Italy, } \\
\text { Japan, Kazakhstan, Lebanon, Malaysia, Malta, Mexico, Morocco, Netherlands, New Zealand, Norway, Philippines, Poland, Portugal, Republic of Korea, } \\
\text { Romania, Russia, Saudi Arabia, Singapore, Slovakia, Slovenia, South Africa, Spain, Sweden, Switzerland, Thailand, Tunisia, Turkey, UK, US, Ukraine, } \\
\text { United Arab Emirates, Venezuela, Vietnam }\end{array}$ \\
\hline & $\begin{array}{l}2 \\
0\end{array}$ & $\begin{array}{l}\text { Algeria, Argentina, Australia, Austria, Belarus, Belgium, Bolivia, Botswana, Brazil, Canada, Chile, China, Colombia, Costa Rica, Czech Republic, } \\
\text { Denmark, Dominican Republic, Ecuador, Egypt, Ethiopia, Finland, France, Germany, Greece, Hong Kong, Hungary, India, Indonesia, Ireland, Israel, } \\
\text { Italy, Japan, Jordan, Kazakhstan, Kenya, Kyrgyzstan, Lebanon, Lithuania, Luxembourg, Malaysia, Mexico, Morocco, Netherlands, New Zealand, }\end{array}$ \\
\hline
\end{tabular}


1 Nigeria, Norway, Oman, Pakistan, Peru, Philippines, Poland, Portugal, Republic of Korea, Romania, Russia, Saudi Arabia, Singapore, Slovakia, 3 Slovenia, South Africa, Spain, Sweden, Switzerland, Thailand, Tunisia, Turkey, UK, US, Ukraine, United Arab Emirates, Uzbekistan, Venezuela, Vietnam

1 Argentina, Australia, Austria, Bahrain, Barbados, Belgium-Luxembourg, Bhutan, Bosnia Herzegovina, Brazil, Bulgaria, Canada, Chile, China, Colombia,

9 Costa Rica, Croatia, Czech Republic, Democratic People's Republic of Korea, Denmark, Djibouti, Egypt, El Salvador, Ethiopia, Faroe Islands, Fiji,

9 Finland, Ethiopia, France, French Guiana, Germany, Ghana, Greece, Guadeloupe, Guatemala, Honduras, Hong Kong, Hungary, India, Indonesia, Iran,

3 Ireland, Israel, Italy, Jamaica, Japan, Jordan, Kenya, Kuwait, Lebanon, Lithuania, Malaysia, Malta, Martinique, Mauritius, Morocco, Netherlands, Nicaragua, Norway, Pakistan, Panama, Peru, Philippines, Poland, Portugal, Qatar, Republic of Korea, Romania, Russia, Réunion, Saudi Arabia, Senegal, Serbia and Montenegro, Singapore, Slovenia, Spain, Sri Lanka, Suriname, Sweden, Switzerland, Thailand, The Former Yugoslav Republic of Macedonia, Tunisia, Turkey, UK, US, United Arab Emirates, Uruguay, Venezuela, Zimbabwe

2 Algeria, Andorra, Argentina, Australia, Austria, Azerbaijan, Bahamas, Bahrain, Belarus, Belgium, Bolivia, Bosnia Herzegovina, Botswana, Brazil,

o Bulgaria, Cameroon, Canada, Chile, China, Colombia, Costa Rica, Croatia, Cuba, Cyprus, Czech Republic, Denmark, Dominican Republic, Ecuador,

0 Egypt, El Salvador, Estonia, Ethiopia, Finland, France, Georgia, Germany, Ghana, Greece, Guatemala, Honduras, Hong Kong, Hungary, Iceland, India,

Rubber

3 Indonesia, Iran, Ireland, Israel, Italy, Jamaica, Japan, Jordan, Kazakhstan, Kuwait, Kyrgyzstan, Latvia, Lebanon, Lesotho, Lithuania, Luxembourg, and metal Macao, Malaysia, Mali, Malta, Mauritania, Mexico, Morocco, Namibia, Netherlands, New Zealand, Nigeria, Norway, Occupied Palestinian Territory, Oman, Pakistan, Panama, Papua New Guinea, Paraguay, Peru, Philippines, Poland, Portugal, Qatar, Republic of Korea, Romania, Russia, Saudi Arabia, Serbia and Montenegro, Singapore, Slovakia, Slovenia, South Africa, Spain, Sri Lanka, Swaziland, Sweden, Switzerland, Syria, Thailand, Trinidad and Tobago, Tunisia, Turkey, UK, US, Uganda, Ukraine, United Arab Emirates, Uruguay, Venezuela, Vietnam, Yemen, Zambia, Zimbabwe

2 Algeria, Andorra, Argentina, Armenia, Australia, Austria, Azerbaijan, Bahamas, Bahrain, Belarus, Belgium, Bolivia, Bosnia Herzegovina, Botswana, 0 Brazil, Brunei Darussalam, Bulgaria, Canada, Chile, China, Colombia, Costa Rica, Croatia, Cyprus, Czech Republic, Denmark, Dominican Republic,

1 Ecuador, Egypt, El Salvador, Estonia, Ethiopia, Finland, France, Georgia, Germany, Ghana, Greece, Guatemala, Honduras, Hong Kong, Hungary, India, 3 Indonesia, Ireland, Israel, Italy, Jamaica, Japan, Jordan, Kazakhstan, Kenya, Kuwait, Kyrgyzstan, Latvia, Lebanon, Lesotho, Lithuania, Luxembourg, Malaysia, Mauritania, Mauritius, Mexico, Mongolia, Morocco, Mozambique, Namibia, Nepal, Netherlands, New Caledonia, New Zealand, Nigeria, Norway, Occupied Palestinian Territory, Oman, Pakistan, Panama, Papua New Guinea, Paraguay, Peru, Philippines, Poland, Portugal, Qatar, Republic of Korea, Romania, Russia, Saudi Arabia, Serbia, Singapore, Slovakia, Slovenia, South Africa, Spain, Sri Lanka, Sweden, Switzerland, Thailand, Turkey, UK, US, Uganda, Ukraine, United Arab Emirates, United Republic of Tanzania, Uruguay, Venezuela, Vietnam, Yemen, Zambia, Zimbabwe

Bold $=$ New countries entering the network

Italics $=$ Exit in the next time period 
Table 5 Brokerage Roles for Rising Powers and traditional players (2003 \& 2013)

\begin{tabular}{|c|c|c|c|c|c|c|}
\hline & \multicolumn{2}{|c|}{ Electric and electrical parts } & \multicolumn{2}{|c|}{ Engines } & \multicolumn{2}{|c|}{ Rubber and metal parts } \\
\hline Countries & 2003 & 2013 & 2003 & 2013 & 2003 & 2013 \\
\hline China & Gatekeeper & Gatekeeper & Representative & Gatekeeper & Liaison & Liaison \\
\hline India & - & Liaison & - & Liaison & Liaison & Liaison \\
\hline Brazil & Representative & Representative & Liaison & Representative & Representative & Representative \\
\hline Russia & Liaison & Liaison & Liaison & Liaison & Liaison & Liaison \\
\hline Germany & Gatekeeper & Gatekeeper & Gatekeeper & Representative & Gatekeeper & Gatekeeper \\
\hline Japan & Gatekeeper & Gatekeeper & Gatekeeper & Gatekeeper & Liaison & Gatekeeper \\
\hline USA & Liaison & Liaison & Liaison & Liaison & Liaison & Liaison \\
\hline
\end{tabular}

Table 6 Weighted E-I index

\begin{tabular}{|c|c|c|c|c|c|c|c|c|c|}
\hline \multirow[b]{2}{*}{ Regions } & \multicolumn{3}{|c|}{ Electric and electrical parts } & \multicolumn{3}{|c|}{ Engines } & \multicolumn{3}{|c|}{ Rubber and Metal parts } \\
\hline & 1993 & 2003 & 2013 & 1993 & 2003 & 2013 & 1993 & 2003 & 2013 \\
\hline East Asia \& Pacific & -0.3474 & -0.32236 & -0.50216 & -0.2549 & -0.34069 & -0.04634 & -0.02039 & -0.13913 & -0.06759 \\
\hline EU28 & -0.07706 & -0.41614 & -0.27589 & -0.63065 & -0.58634 & -0.41401 & -0.18659 & -0.55771 & -0.36084 \\
\hline Eurasia & 1 & 0.949512 & 0.904893 & 1 & 1 & 0.987661 & 1 & 0.902385 & 0.671102 \\
\hline Latin America \& Caribbean & 0.663678 & 0.201331 & 0.287611 & 0.567378 & 0.555738 & 0.711451 & 0.301434 & 0.40303 & 0.352585 \\
\hline Middle East \& North Africa & 0.85627 & 0.529461 & 0.55586 & 1 & 0.84456 & 0.893678 & 0.857143 & 0.739345 & 0.78744 \\
\hline North America & 0.120721 & 0.185078 & 0.283248 & -0.29624 & -0.30388 & -0.08361 & -0.22979 & -0.23432 & 0.201421 \\
\hline Other European & 1 & 0.980328 & 0.959196 & 1 & 0.980081 & 1 & 0.931548 & 0.555556 & 0.608974 \\
\hline South Asia & 1 & 1 & 0.508042 & 1 & 1 & 1 & 0.444444 & -0.11765 & 0.744134 \\
\hline Sub-Saharan Africa & 1 & 0.402191 & 0.372483 & 1 & -0.01757 & 0.586468 & 1 & 0.441259 & 0.423556 \\
\hline Central Asia & - & 1 & 1 & - & 1 & 1 & - & 1 & 1 \\
\hline
\end{tabular}

The Weighted E-I score can range from 1 to -1 .

Positive values indicate that the majority of trade (value) occurs outside the region.

Negative score indicates that majority of trade (value) is regional. 


\section{Figures}

\section{Figure 1}

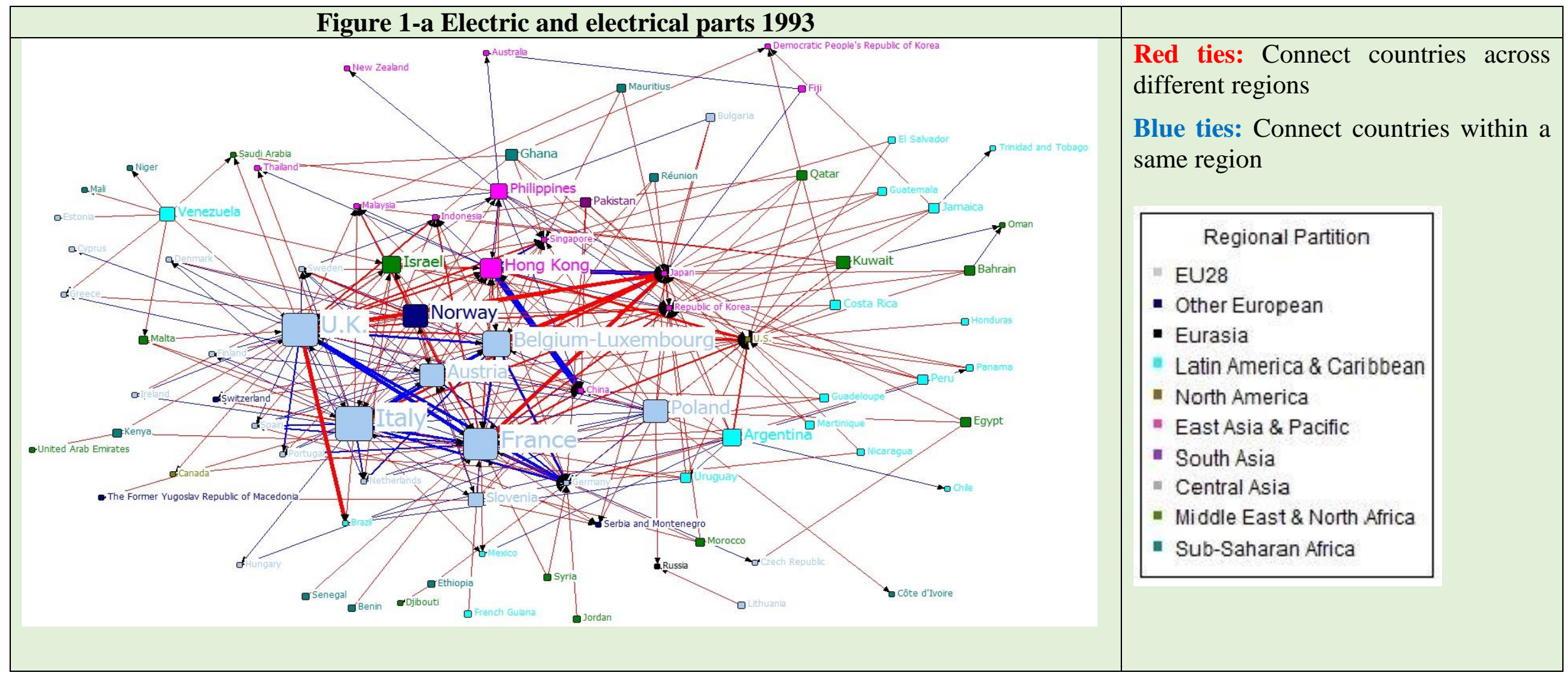




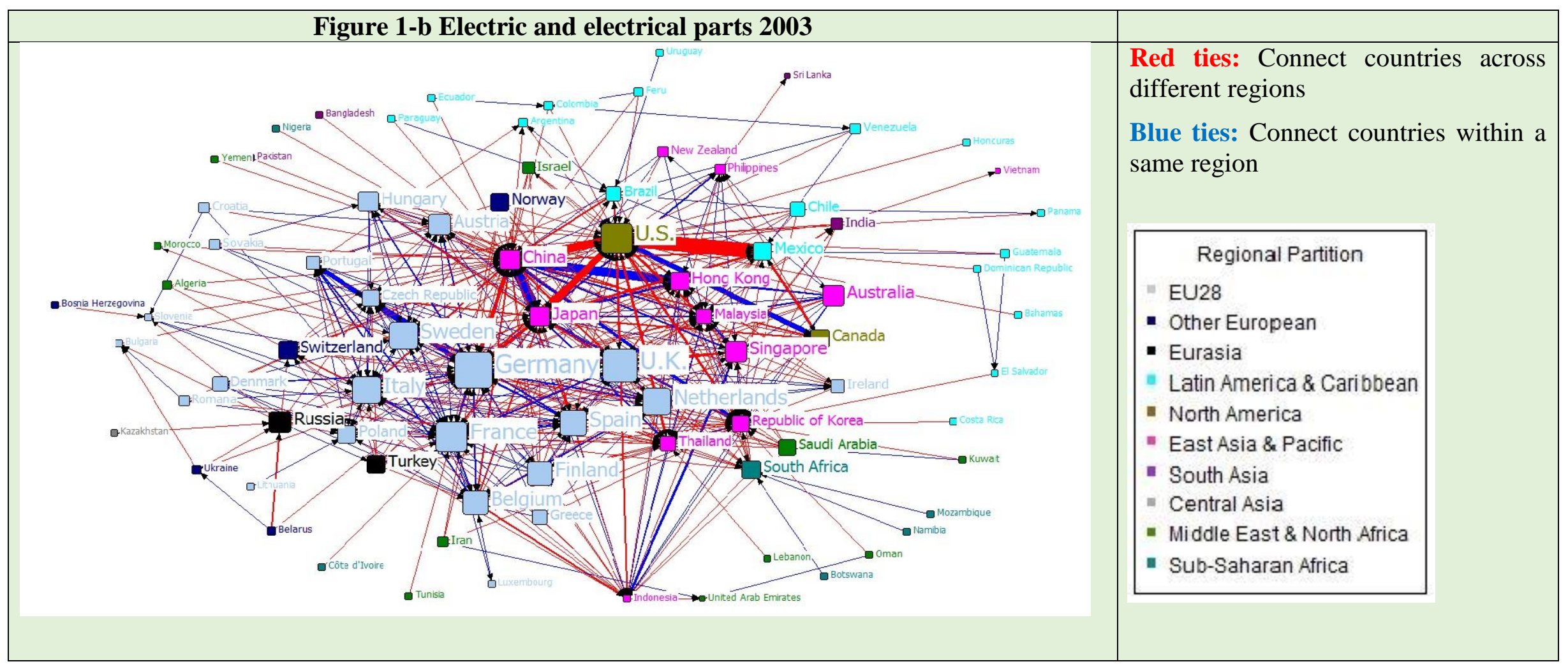




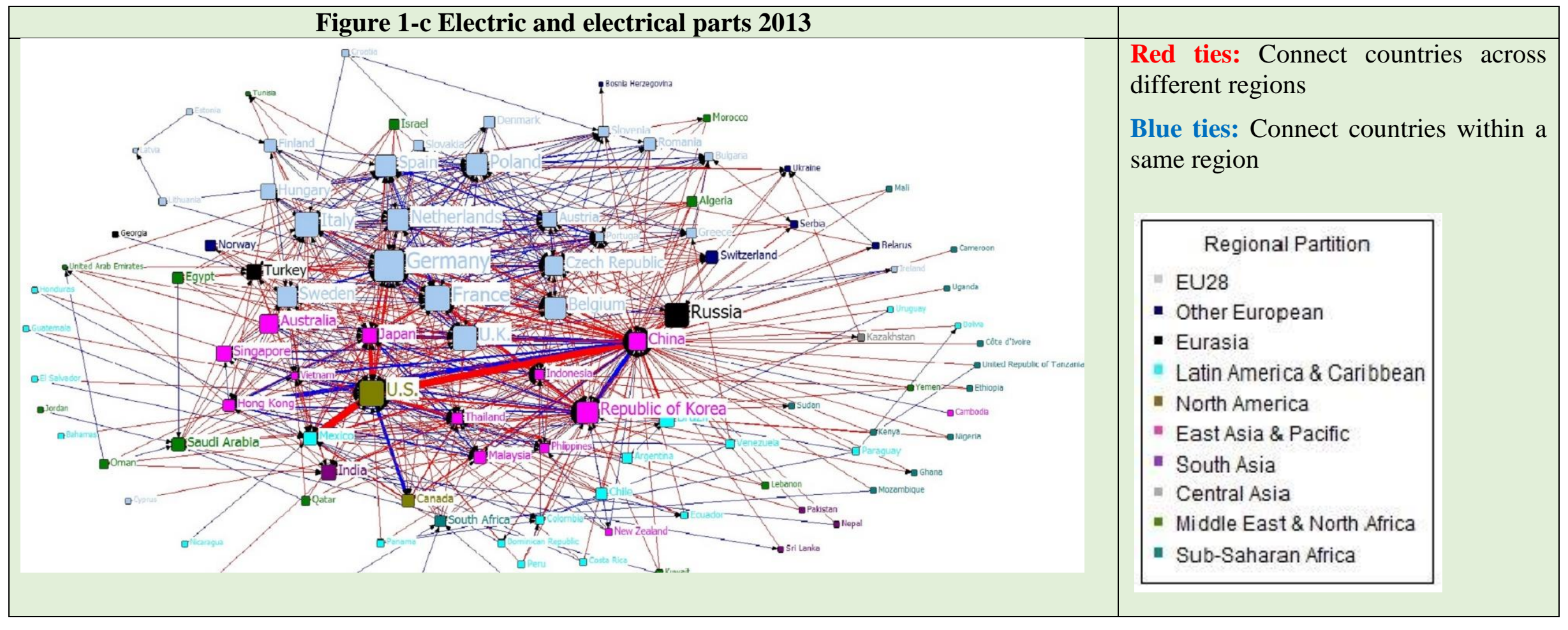




\section{Figure 2}

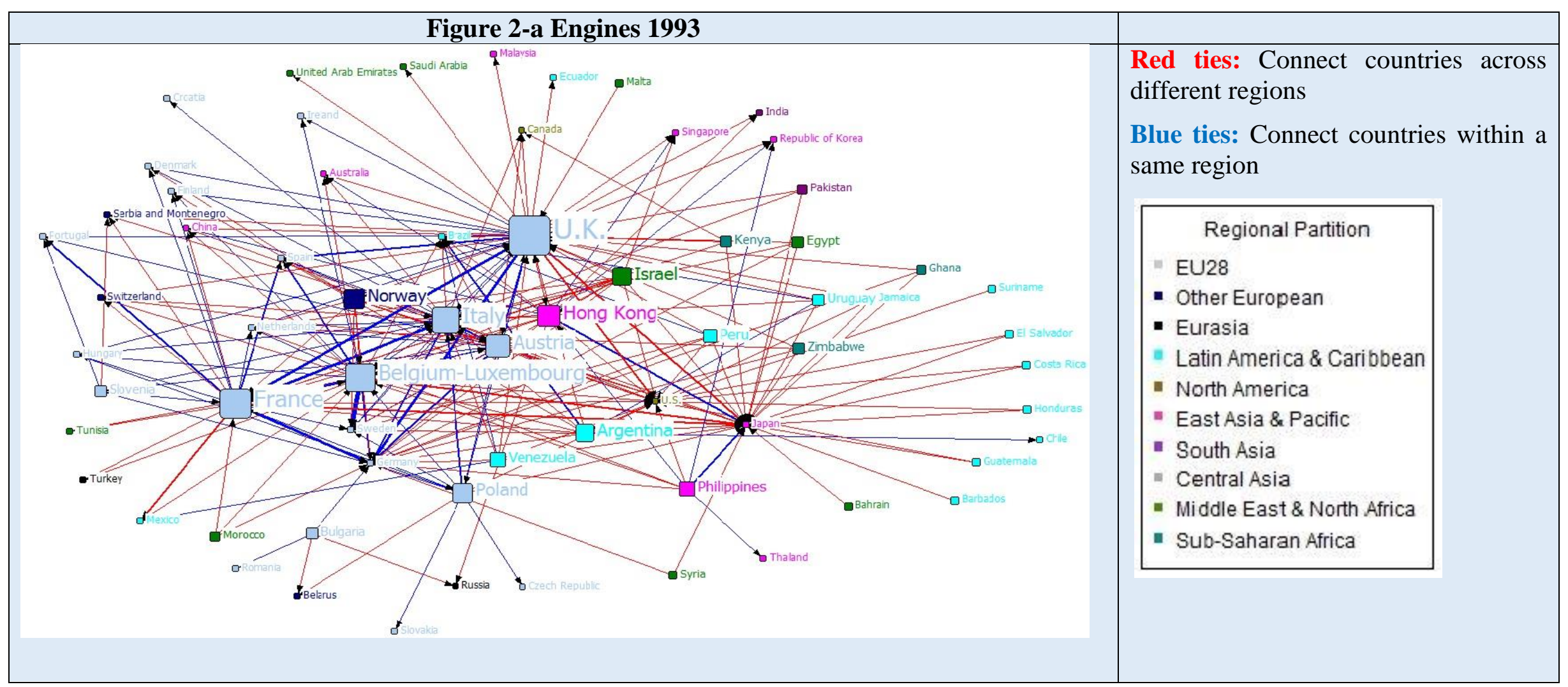




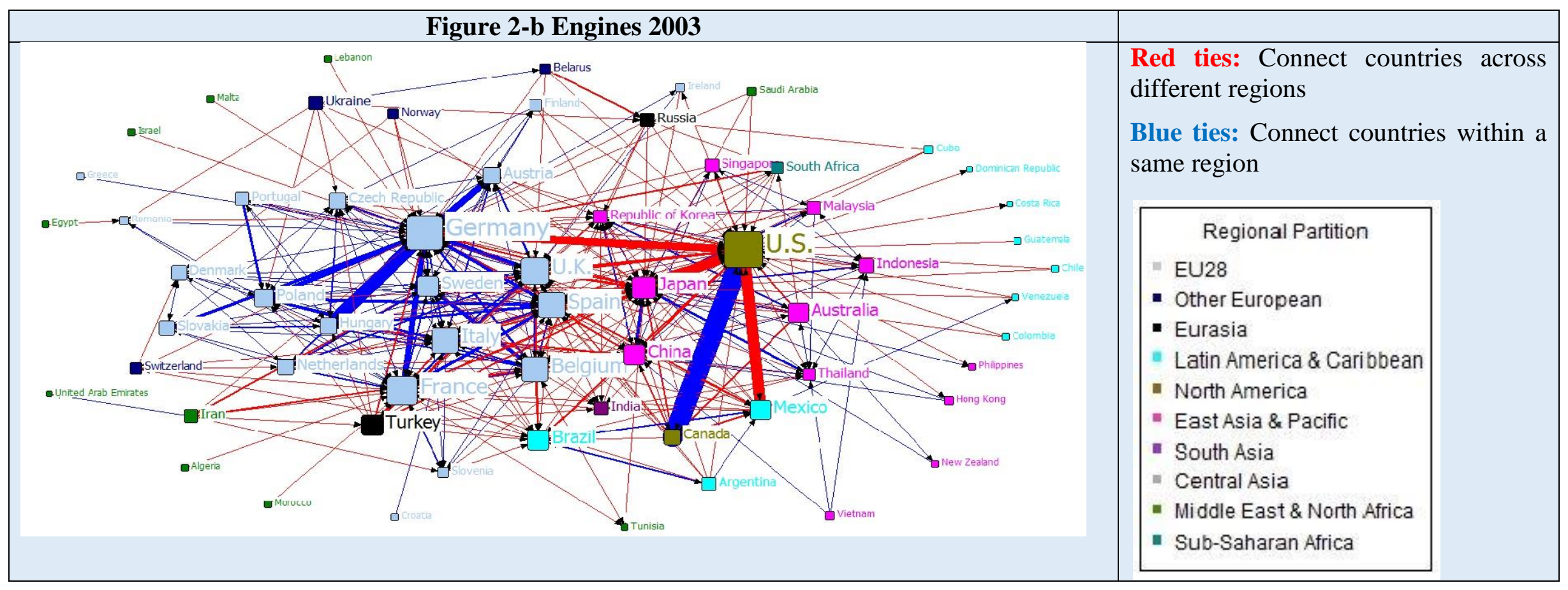




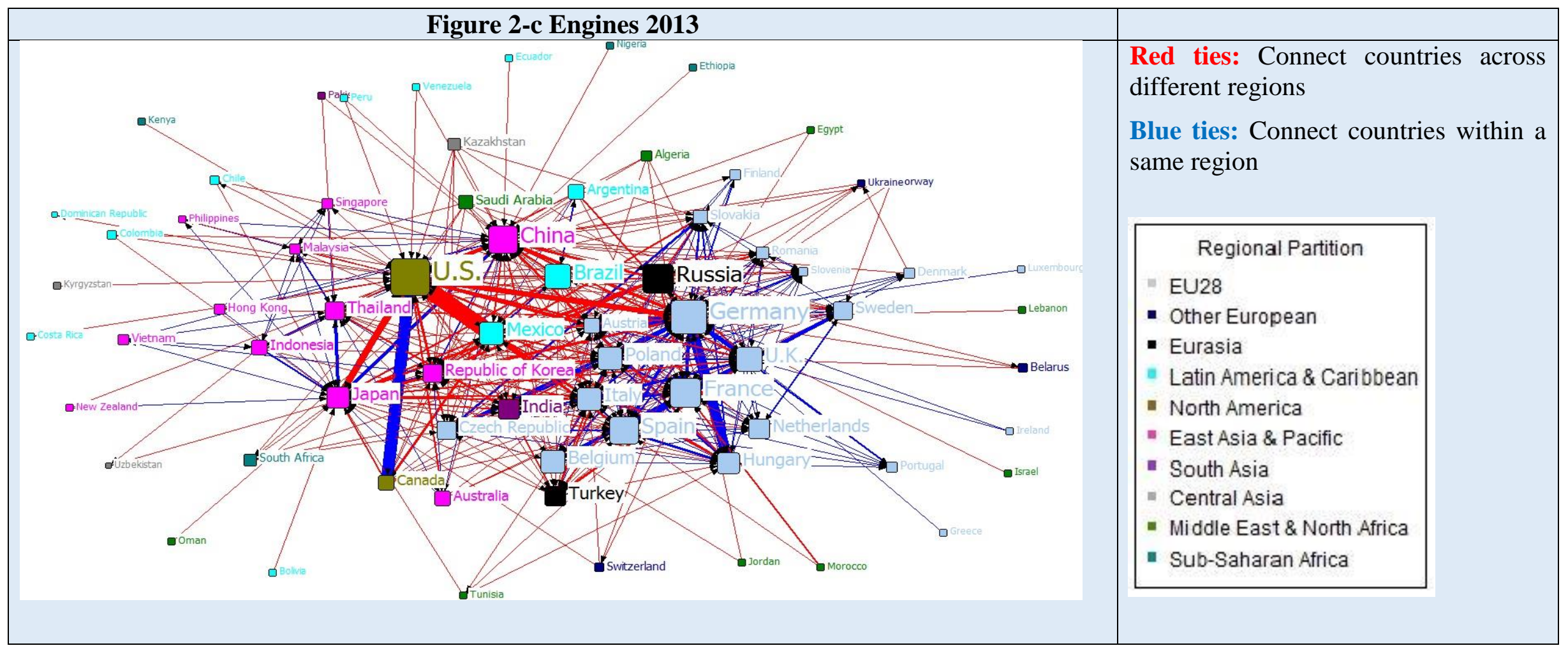




\section{Figure 3}

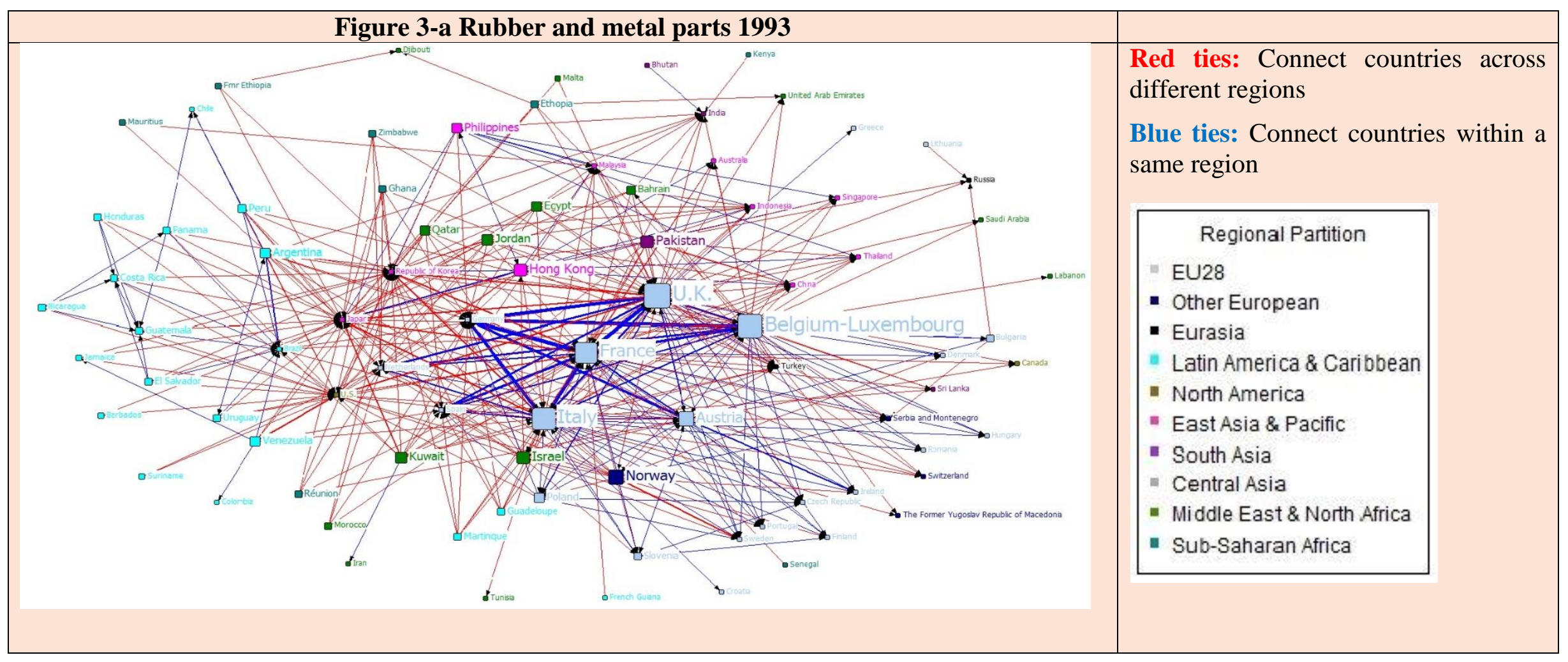




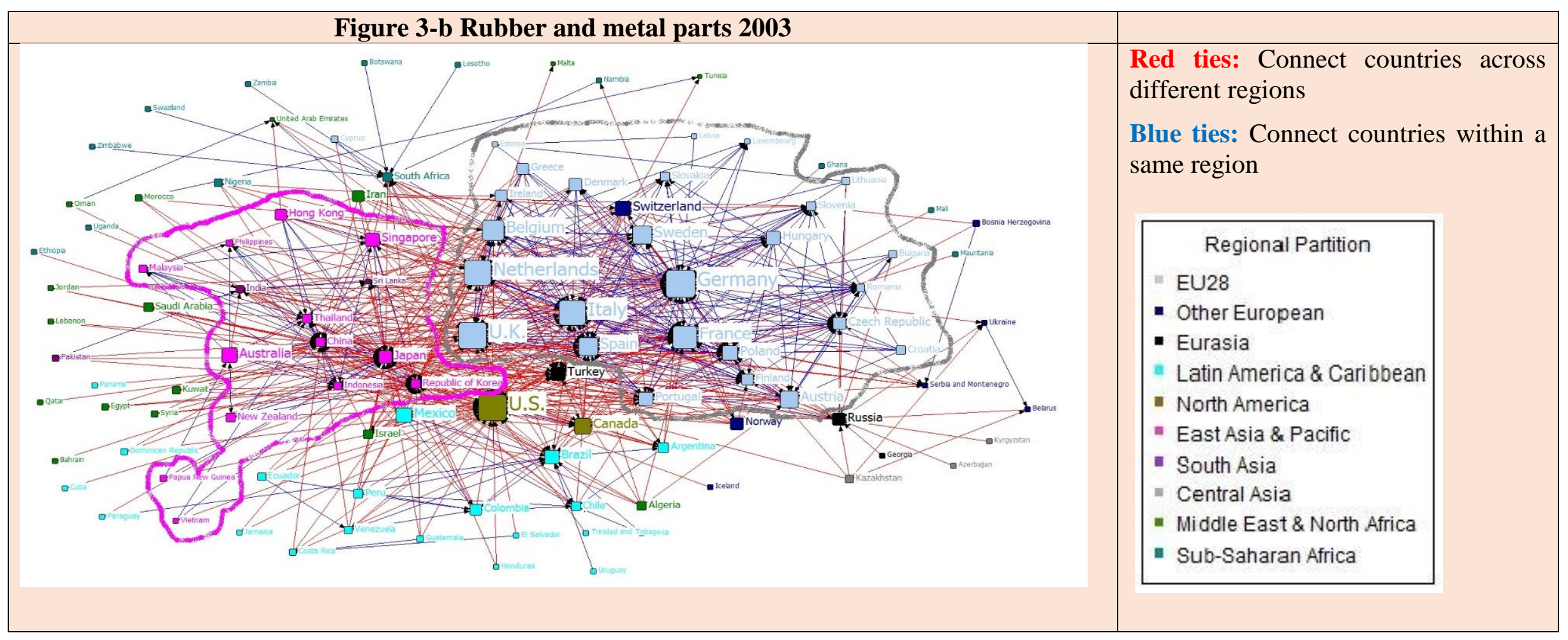




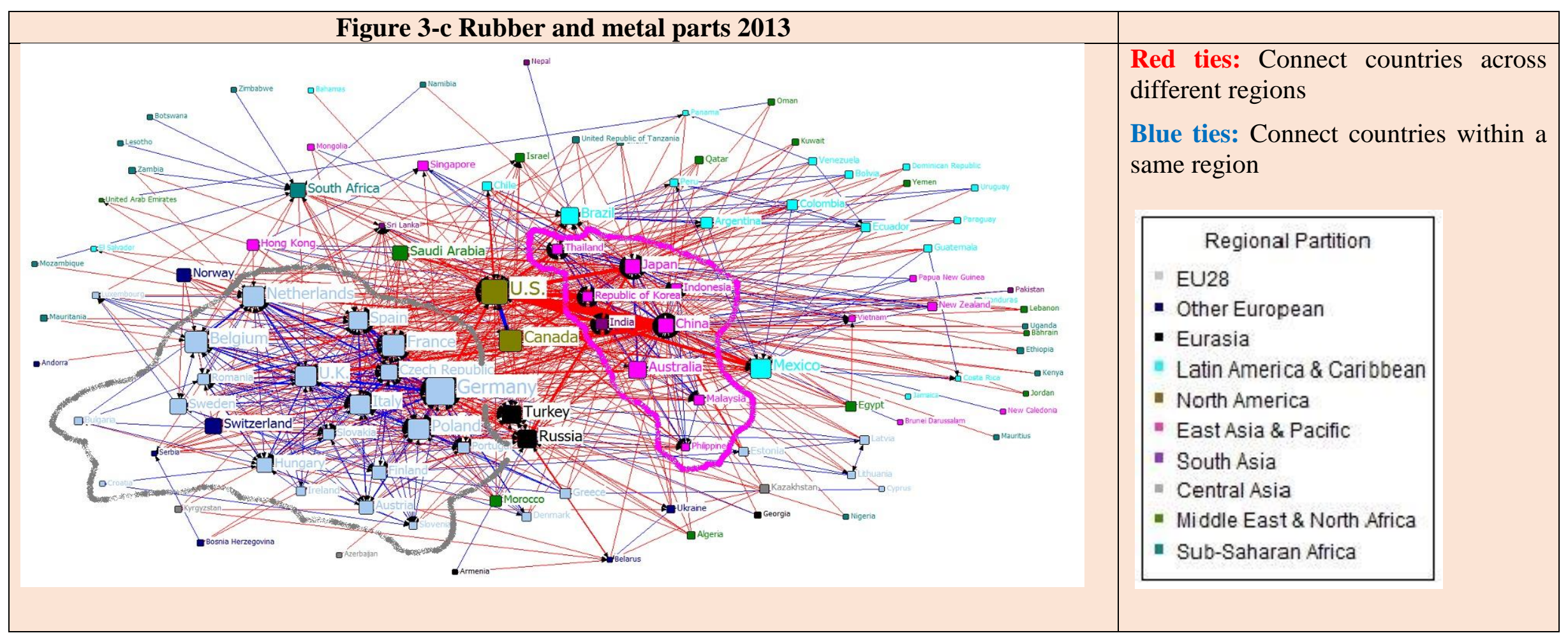




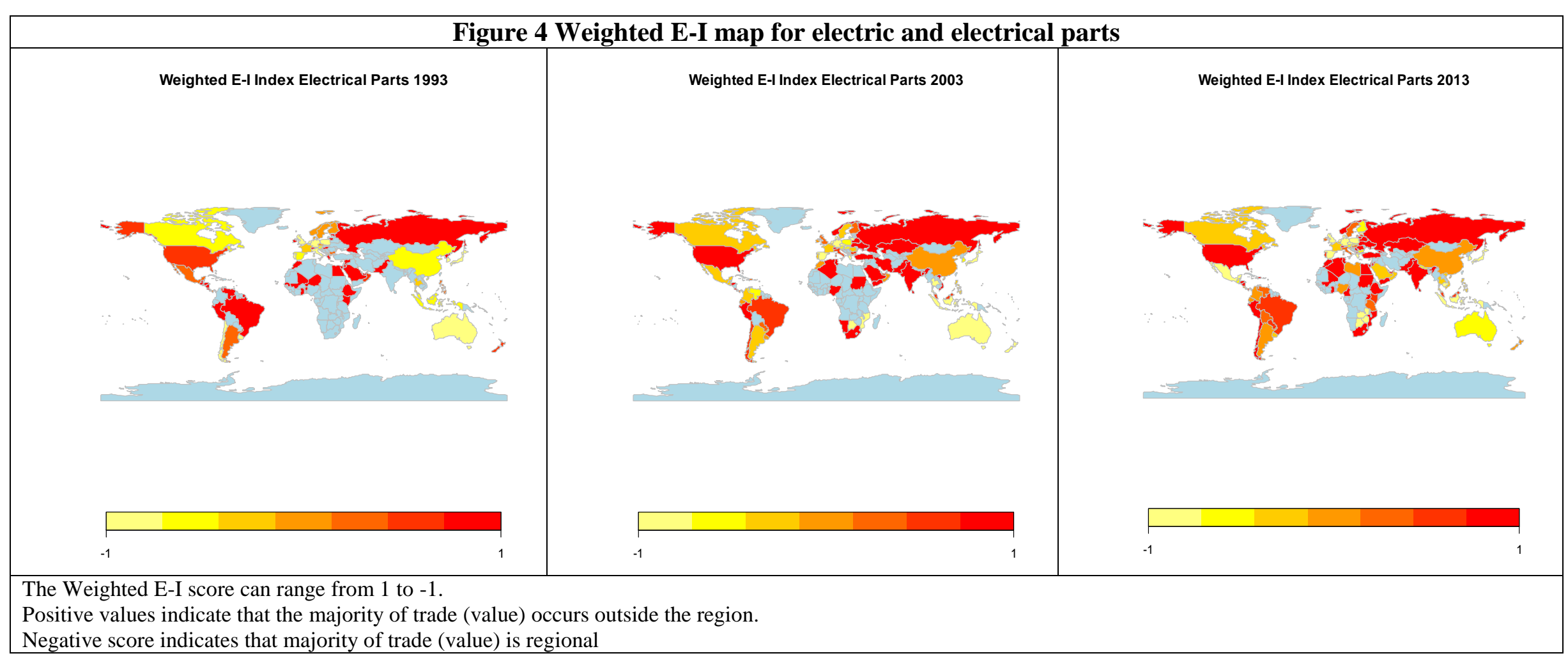




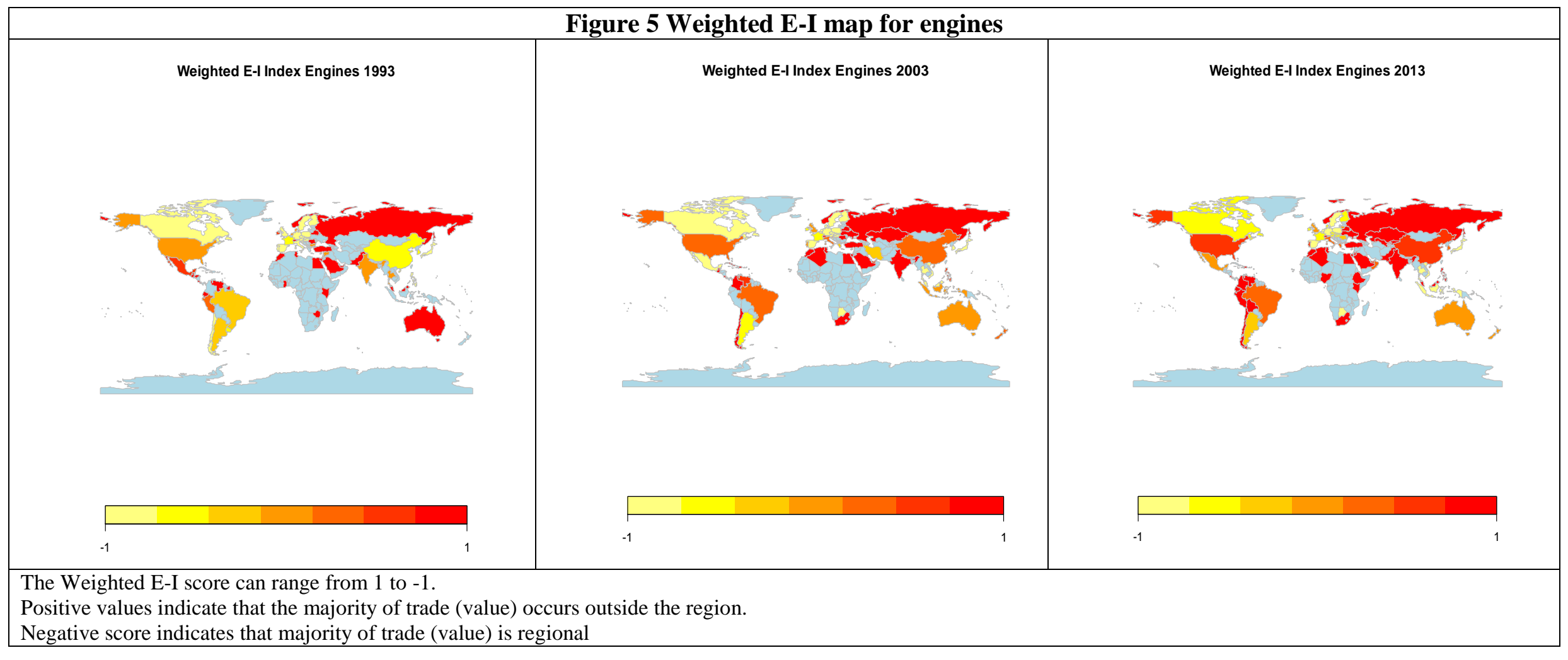




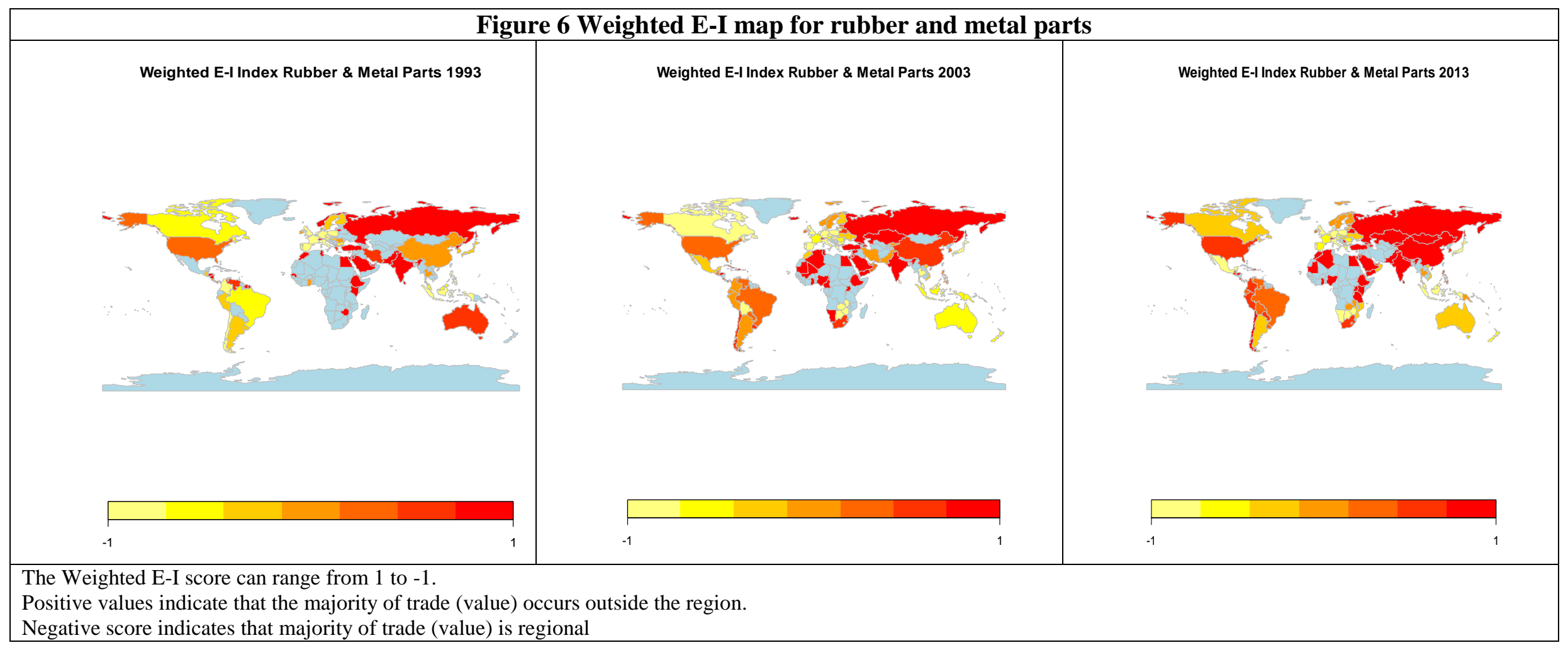


${ }^{1}$ In this paper we use the term 'rising powers' to refer to the BRICs.

${ }^{2}$ Data are tabulated using importer records, more reliable than the corresponding exporter records.

${ }^{3}$ Our classification is similar to the parts product listings adopted by the US Office of Aerospace and Automotive Industries (OAAI). Like OAAI, our classification attempts to closely approximate to the core automotive industry by excluding certain items, for example parts explicitly listed for motorcycles, golf-carts, snowmobiles, agricultural equipment, etc.

${ }^{4}$ These were chosen as reference years in order to compare the recent structure of the components trade with that prevailing a decade before. Due to the sharp decrease in overall trade volume after 2008, during the global economic crisis, that year was chosen as the most recent reliable year.

${ }^{5}$ Out-strength Centrality is the sum of bilateral trade relationships weighted for their relative value, so it is a degree centrality calculated on value rather than binary data. Amighini and Gorgoni (2013) show how the ranking of the most central country in the network changes depending on which centrality measure is used. The countries that have more trade partners are not necessarily those that account for most of the trade.

${ }^{6}$ To perform the core-periphery analysis we used the categorical procedure on valued data using the CORR algorithm (Borgatti and Everett, 1999). 